\title{
SALUD MENTAL DE LOS ESTUDIANTES UNIVERSITARIOS EN TIEMPOS DE PANDEMIA COVID-19
}

\author{
Mental health in college students in times of COVID-19 pandemic
}

Héctor William Carlos Cruces ${ }^{1, a}$

\footnotetext{
${ }^{1}$ Docente de la Facultad de Ciencias Económicas y Negocios Internacionales, Universidad Nacional San Luis Gonzaga. Ica, Perú.

${ }^{a}$ Doctor en Educación.
}

Actualmente en el mundo, el principal problema en salud pública es la pandemia, ocasionada por el coronavirus COVID 19, que está afectando a la sociedad en todos sus niveles y estratos. como lo hace notar la Organización Mundial de salud (OMS) habiendo registrado a la fecha alrededor de 182,6 millones de casos de coronavirus (SARS-CoV-2), un estimado de fallecidos de 3.9 millones de personas, el coronavirus que se originó en la ciudad China de Wuhan, extendiéndose a todos los países del mundo, , donde el Perú de acuerdo al Ministerio de Salud (MINSA) registra a la fecha 2.066.677 casos confirmados de coronavirus (COVID19) registrando un estimado de 193.389 fallecidos, debido a la falta de tratamientos específicos, efectivos, y precario sistema de salud (1).

El gobierno se vio obligado adoptar diferentes medidas imperativas, como el decreto de estado de emergencia, la medida de aislamiento social, el confinamiento en los hogares, limitaciones de tránsito, restricciones laborales, toque de queda, distanciamiento social, el uso de máscaras entre otras para limitar los contactos sociales de las personas, ocasionando inseguridad entre los jóvenes, cambiándole su ritmo de vida, extrañando ver a sus amigos, ir al cine, discoteca, o practicar deporte, en lo educativo las clases en aulas universitarias, se trasladaron a casa ,invadiendo los espacios de la sala, comedor, dormitorio, etc., conviviendo en forma de pantalla con una laptop, computadora, celular, donde los estudiantes no solo enfrentan las novedades de las clases virtuales, sino un porcentaje el abandono de las universidades ante la disminución de los ingresos familiares, así mismo diferentes causas adversas que la pandemia ha revelado como las desigualdades socioeconómicas, por la falta de electricidad, internet, medios digitales, afectando la salud mental de los estudiantes, donde un gran porcentaje de la población universitaria experimentó estados de estrés, ansiedad, psicosomáticas, depresión, desvalorización personal, problemas de sueño, tristeza, falta de concentración, incluso ideaciones suicidas, siendo de un manejo difícil, produciendo diferentes sintomatologías como dolor de cabeza, sensación falta de aire, malestar del cuerpo, diarreas, dolor de pecho, síntomas que en muchos casos es confundido con el COVID-19, por el cual muchas personas acuden a los hospitales, exponiéndose al inminente peligro de contagio del temido virus, complicándose la salud mental de los estudiantes cuando un familiar ha fallecido o ha dado positivo al COVID-19.

El estudio de Cobo, halló los siguientes síntomas (de moderados a severos) en estudiantes universitarios: estrés (31.9\%), psicosomáticos (5.9\%), problemas para dormir (36.3\%), disfunción social en la actividad diaria (9.5\%) y depresivos (4.9\%), especialmente en el grupo de las mujeres y en los estudiantes más jóvenes (18-25 años), en este último grupo, también se detectó ansiedad $(40.3 \%)$ con mayores niveles en los hombres (2); Otra investigación universitaria, identifico aumentos en síntomas de depresión, ansiedad, estrés postraumático, ideación suicida y problemas de sueño (3). 
Así mismo, el estudio sobre desarrollo cerebral por varios institutos federales de salud ,sobre 11,000 niños mostraron que aquellos que pasan más de 2 horas al día frente a una pantalla de algún dispositivo, obtuvieron calificaciones más bajas en el colegio, de otros que habían leído al menos un libro, la tesis concluye que los cerebros de ambos tipos de estudiantes son diferentes, la exposición regular a las pantallas adelgaza la corteza cerebral, en adultos encontró características afines entre quienes utilizan las pantallas continuamente y la depresión (4).

La mayoría de las instituciones universitarias cuentan con la Facultad de psicología, debiendo participar en actividades grupales a distancia, enfatizando el autocuidado y el cuidado de los demás, estrategias de promoción y prevención de la salud mental, comprensión de los síntomas de alerta que deben guiarnos para consultar a los profesionales de la salud, como gestión institucional agenciar puentes con los estudiantes, buscar mejorar el estrés, la ansiedad y otros síntomas, de esta manera tratar de optimizar el bienestar biopsicosocial de los estudiantes universitarios.

El impacto de la pandemia todavía no revela la dimensión de daño en los estudiantes en cuanto a su salud mental, es difícil dar consejos simples para una situación tan compleja como la que estamos viviendo, donde la parte humana es lo más difícil, vamos a tener todos problemas de salud mental, como un síndrome de estrés pandémico.

\section{REFERENCIAS BIBLIOGRÁFICAS.}

1. Ministerio de Salud (MINSA). Casos confirmados por coronavirus COVID-19. Comunicado $\mathrm{N}^{\circ}$ 599 de fecha 04 de julio 2021

2. González N, Tejeda A, Méndez C, Ontiveros Z. Impacto psicológico en estudiantes universitarios mexicanos por confinamiento durante la pandemia por Covid-19. Scielo PrePrint. 2020.(Internet). México; 2020. (Citado el 14 de Julio 2021) Disponible en: https:// buff.ly/2NBXGIP.

3. Cobo R, Vega A, García D. Consideraciones institucionales sobre la Salud Mental en estudiantes universitarios durante la pandemia de Covid-19. CienciAmérica 2020;9(2):277-84. (Internet). Ecuador; 2020. (Citado el 20 de Julio 2021) Disponible en: https:// buff.ly/3blx5LT.

4. Bowles, N. La interacción humana es un lujo en la Era de las pantallas. The New York Times. 2019.(Internet). Nueva York, Estados Unidos;2019. (Citado el 30 de Julio 2021) Disponible en: https://www.nytimes.com/es/2019/03/26/espanol/opinion/tecnologia-pantallas-contacto.html 